University of Windsor

Scholarship at UWindsor

Research Result Summaries

2019

\title{
Facilitating the Development of Shared Athlete Leadership: Insights from Intercollegiate Coaches
}

\author{
Ashley M. Duguay \\ University of Windsor, duguay7@uwindsor.ca \\ Todd M. Loughead \\ University of Windsor, loughead@uwindsor.ca \\ Matt D. Hoffmann \\ matthieu.hoffmann@gmail.com \\ Jeffrey G. Caron \\ University of Montreal, jeffrey.caron@umontreal.ca
}

Follow this and additional works at: https://scholar.uwindsor.ca/research-result-summaries

Consistent with the TCPS 2 (4.7) this is a research summary provided to participants and should not be considered a formal publication of results.

\section{Recommended Citation}

Duguay, A. M., Loughead, T. M., Hoffmann, M. D., \& Caron, J. G. (2019). Facilitating the Development of Shared Athlete Leadership: Insights from Intercollegiate Coaches. Retrieved from

https://scholar.uwindsor.ca/research-result-summaries/102

This Completed Summary is brought to you for free and open access by Scholarship at UWindsor. It has been accepted for inclusion in Research Result Summaries by an authorized administrator of Scholarship at UWindsor. For more information, please contact scholarship@uwindsor.ca. 


\section{Facilitating the Development of Shared Athlete Leadership: Insights from Intercollegiate Coaches}

A growing body of literature supports the shared nature of athlete leadership, where athletes engage in a collaborative process of influence through formal or informal leadership positions. This shared approach has been positively associated with a number of characteristics of effective team functioning including team identification, collective efficacy, cohesion, and team resilience. Despite this, scant research is available on how coaches are developing shared athlete leadership in their teams. As such, the purpose of the present study was to examine intercollegiate coaches' practices for facilitating the development of shared athlete leadership. Data from semi-structured interviews with 15 current U Sports $(n=10)$ and Canadian Collegiate Athletics Association $(n=5)$ head coaches were analyzed using inductive reflexive thematic analysis. The coaches described their desire to empower athletes as a motive for adopting shared approaches to athlete leadership. In turn, coaches discussed various practices for facilitating the development of shared athlete leadership in their teams. Specifically, coaches' practices were discussed in relation to the use of leadership groups and alternative leadership structures (e.g., rotating captaincy, defined leadership roles, and 'captainless' teams), the creation of a positive team environment, and deliberate athlete leadership development efforts. The findings provide insights into how coaches can facilitate the development of shared athlete leadership in their teams. 